\title{
Erratum: Acquired immunity and asymptomatic reservoir impact on frontline and airport Ebola outbreak syndromic surveillance and response
}

Ernest Tambo ${ }^{1,2,3,4^{*}}$ and Xiao-Nong Zhou ${ }^{2,3}$

\section{Erratum}

After publication of this work [1], we noted an inversion of the first and family names of the author Xiao-Nong Zhou. The author list should be corrected as follows.

Ernest Tambo and Xiao-Nong Zhou.

\section{Competing interests}

The authors declare that they have no competing interests.

\section{Authors' contributions}

This study was conceived and designed by ET. XNZ provided guidance on the technical aspects of the study. ET and XNZ provided additional detailed scientific and technical information and commentary on the manuscript. ET assembled the final version and performed extensive revisions. All authors read and approved the final manuscript.

\section{Author details}

${ }^{1}$ Sydney Brenner Institute for Molecular Bioscience, School of Medical Sciences \& School of Public Health, University of the Witwatersrand, Johannesburg, South Africa. ${ }^{2}$ National Institute of Parasitic Diseases, Chinese Center for Disease Control and Prevention, Shanghai 200025, People's Republic of China. ${ }^{3}$ WHO Collaborating Centre for Malaria, Schistosomiasis and Filariasis, Key Laboratory of Parasite and Vector Biology, Ministry of Health, Shanghai 200025, People's Republic of China. ${ }^{4}$ Département de Biochimie et Science Pharmaceutiques, Université des Montagnes, Bagangté, République du Cameroun.

Received: 22 January 2015 Accepted: 26 January 2015

Published online: 10 April 2015

\section{References}

1. Tambo E, Xiao-Nong Z. Acquired immunity and asymptomatic reservoir impact on frontline and airport Ebola outbreak syndromic surveillance and response. Infect Dis Poverty. 2014;3:41.

\footnotetext{
* Correspondence: tambo0711@gmail.com

${ }^{1}$ Sydney Brenner Institute for Molecular Bioscience, School of Medical Sciences \& School of Public Health, University of the Witwatersrand, Johannesburg, South Africa

${ }^{2}$ National Institute of Parasitic Diseases, Chinese Center for Disease Control and Prevention, Shanghai 200025, People's Republic of China

Full list of author information is available at the end of the article
}

Submit your next manuscript to BioMed Central and take full advantage of:

- Convenient online submission

- Thorough peer review

- No space constraints or color figure charges

- Immediate publication on acceptance

- Inclusion in PubMed, CAS, Scopus and Google Scholar

- Research which is freely available for redistribution 